\title{
Bacterial Artificial Chromosome Libraries of Pulse Crops: Characteristics and Applications
}

\author{
Kangfu Yu \\ Greenhouse and Processing Crops Research Centre, Agriculture and Agri-Food Canada, 2585 County Road 20, Harrow, \\ ON, Canada NOR $1 G 0$
}

Correspondence should be addressed to Kangfu Yu, kangfu.yu@agr.gc.ca

Received 27 April 2011; Revised 29 May 2011; Accepted 30 May 2011

Academic Editor: J. Birchler

Copyright ( $\odot 2012$ Kangfu Yu. This is an open access article distributed under the Creative Commons Attribution License, which permits unrestricted use, distribution, and reproduction in any medium, provided the original work is properly cited.

Pulse crops are considered minor on a global scale despite their nutritional value for human consumption. Therefore, they are relatively less extensively studied in comparison with the major crops. The need to improve pulse crop production and quality will increase with the increasing global demand for food security and people's awareness of nutritious food. The improvement of pulse crops will require fully utilizing all their genetic resources. Bacterial artificial chromosome (BAC) libraries of pulse crops are essential genomic resources that have the potential to accelerate gene discovery and enhance molecular breeding in these crops. Here, we review the availability, characteristics, applications, and potential applications of the BAC libraries of pulse crops.

\section{Introduction}

"Pulse crops" refers to a group of more than sixty different grain legumes grown around the world. Pulse crop seeds, which are important for human nutrition, typically have 20 $25 \%$ protein and $40-50 \%$ starch, are rich in dietary fibre, and usually have only small amounts of oil. Pulse protein is high in the amino acids lysine and methionine, making pulses nutritionally complementary to cereals, which are deficient in these two essential amino acids. Despite the importance of pulse crops for nutrition and food security in developing countries, they are considered to be minor on a global scale, and pulse genomes have been less extensively studied than those of major crops.

Large insert genomic DNA libraries are essential genomic resources for physical mapping, positional cloning, and genome sequencing of higher eukaryotes [1-4]. The bacterial artificial chromosome (BAC) cloning system has become an invaluable tool in genomic studies because of its ability to stably maintain large DNA fragments and its ease of manipulation $[2,5,6]$. BAC libraries are an important resource for the development of molecular markers that can be used for marker-assisted selection (MAS) for desirable agronomic traits. Development of simple sequence repeat (SSR) markers from $\mathrm{BAC}$-end sequences is very cost effective $[7,8]$ and offers genome-wide coverage as all repeat types are systematically sampled in the randomly selected BACs [9].

Since the development of the BAC vector in 1989 [10], many BAC libraries have been developed for the major crop species, such as wheat, rice, corn, and soybean. In recent years, however, BAC libraries have also been developed for several pulse crops including mungbean (Vigna radiate L.), cowpea ( $V$. unguiculata L.), lupin (Lupinus angustifolius L.), chickpea (Cicer arietinum L.), pigeonpea (Cajanus cajan L.), field pea (Pisum sativum L.), Lima bean (Phaseolus lunatus L.), and common bean (P. vulgaris L.) (Table 1). Understanding the characteristics of these libraries would facilitate the utilization of these resources in genomic studies of pulse crops. In this paper, we will review the characteristics and utilizations of the BAC libraries in pulse crops and will discuss the potential applications of these libraries in pulse crop genomic research.

\section{Mungbean (Vigna radiata)}

Mungbean ( $V$. radiata) is an important grain legume in Asia, particularly India. It has $25-28 \%$ of protein; $4.5 \%$ of fibre, and $1.5 \%$ of fat [11]. It is eaten mainly as a dry seed but is also used for forage and as a vegetable in the form 
of sprouted seeds or green pods. Mungbean is a relatively low-yielding crop that suffers from abiotic stresses such as heat and drought as well as many biotic stresses including foliar diseases and insect damage, particularly from bruchid (Callosobruchus chinensis), a weevil-like insect that can account for up to $40 \%$ loss of stored seed.

Miyagi et al. [12] constructed two mungbean BAC libraries that together gave a $3.5 \times$ coverage of the $587 \mathrm{Mb}$ genome (Table 1). The libraries were constructed from both radiata ssp. (green gram) and its wild progenitor sublobata ssp. (golden gram). By screening these libraries using RFLP probes, including Mgm213 that is very closely linked $(1.3 \mathrm{cM})$ to the major locus conditioning bruchid resistance, two PCR-based markers were developed closely linked to this major locus. This information should facilitate the introgression of this resistance locus into agriculturally valuable cultivars. These libraries also could be used in the development of other PCR-based markers linked to other desirable traits.

\section{Lupin (Lupinus angustifolius)}

Narrow-leafed lupin (L. angustifolius) is a pulse crop native to the Mediterranean. It is grown as green manure as far north as 60 degrees $\mathrm{N}$ latitude. Used as a feed crop, the seeds contain $32-34 \%$ of protein. The plant is also used as a medicinal source of vitamins and of insecticides [26]. Some varieties can grow on marginal soil, and they have been used for the removal of heavy metals from contaminated soil [29]. Crop improvement, however, has been slow, partly due to lack of knowledge of its genomic structure.

In 2006, Kasprzak et al. [26] reported the construction of a BAC library (Table 1) from diploid L. angustifolius L. cv. Sonet. This genotype has valuable agronomic traits such as low alkaloid content (iuc), nonshattering pods ( $t a$ and $l e$ ), and soft seed coat (moll). The library has been used for cytogenetic mapping of mitotic metaphase chromosomes to karyotype L. angustifolius. This first lupin ideogram was produced using BAC-fluorescence in situ hybridization (FISH), combined with primed in situ DNA labelling (PRINS) and computer measurement of chromosomes [30]. It was also used to produce a BAC-end sequence tag (BEST) marker, which facilitated aligning a new reference genetic map of lupin with the Lotus japonicus genome sequence [31].

\section{Cowpea (Vigna unguiculata)}

Cowpea ( $V$. unguiculata) is the major source of dietary protein for millions of people in Africa and other regions of the developing world. Humans consume the seeds predominantly in the dry form, but fresh pods and green peas are eaten in some areas. Cowpea hay is an important fodder for animals in parts of west Africa [32]. Cowpea is well adapted to drought and heat and can grow where few other food crops can [33].

To date, a moderate number of SSR and single nucleotide polymorphism (SNP) markers have been developed to provide a reasonably densely covered map; however, the physical map needs work, and there has been little trait mapping or molecular breeding [34]. Two independent cowpea BAC libraries have been developed (Table 1), and high-information-content fingerprinting analysis [35] of 60,000 of these clones has allowed their assembly into 790 contigs with an average of 52 BACs per contig. This assembly represents $10 \times$ coverage of the genome. End sequencing yielded 30,611 high-quality BESs (BAC end sequences) with an average length of $674 \mathrm{bp}$ for a total of $20.6 \mathrm{Mb}$. In a BLAST search against a nonredundant protein database, 891 of the BESs had significant hits [20].

\section{Chickpea (Cicer arietinum L.)}

Chickpea (C. arietinum L.) is the third most important pulse crop in the world [FAO 2003, http://www.fao.org/]. Chickpea is primarily produced for human consumption both as whole seeds and as flour (dahl). The larger-seeded type, also known as garbanzo beans, is used in salads and vegetable mixes. Chickpea was one of the first grain legumes to be domesticated in the old world although there is considerable debate as to the exact area of origin [36]. The crop is highly susceptible to fungal diseases, particularly fusarium wilt (Fusarium oxysporum) and ascochyta blight (Ascochyta rabiei, Didymella rabiei), so attempts to improve yield have not been very successful to date. Any genetic resources that could assist in developing resistant cultivars would be of significant benefit to people who depend on plant sources for their protein.

Studies of resistance to ascochyta blight indicate that it is inherited in a complex and quantitative manner [37] and, although moderate resistance has been detected in existing accessions within germplasm collections [38, 39], the resistance is likely recessive, which hinders the development of superior cultivars. In addition, there is a paucity of genetic diversity among cultivars and wild accessions of $C$. arietinum, making it difficult to find material to use in crop improvement programs $[40,41]$.

The first genetic map of chickpea was developed in 1997 [42], but it had a low marker density. There are several molecular tools now available for chickpea improvement, including molecular genetic maps [37, 43-45] and identified quantitative trait loci (QTLs) $[9,46,47]$, but new resources must be developed to obtain markers close enough to the loci of interest to be of use in MAS.

Rajesh et al. [21] reported the construction of a BAC library from germplasm of the line FLIP 84-92C (Table 1) in order to investigate resistance to fusarium wilt. He screened the library with a Sequence Tagged Microsatellite Site (STMS) marker, Ta96, which is tightly linked $(1 \mathrm{cM})$ to a gene for fusarium wilt resistance (Foc3) and isolated two clones with a combined insert size of $200 \mathrm{~kb}$. This marker was mapped to linkage group 2 where other wilt $R$ genes against races $1,3,4$, and 5 of the same pathogen were located [33]. These clones overlapped at the interior sequences and, upon homology search, showed resemblance over $165 \mathrm{bp}$ to a ribosomal protein of Medicago truncatula (mtgsp005e03), a close relative of chickpea, and to a zinc finer-like protein of Arabidopsis (AT1G14580.1). Further screening of the library with markers positioned near the $\mathrm{R}$ genes on linkage group 2 
TABLE 1: Bacterial artificial chromosome (BAC) libraries of pulse crops.

\begin{tabular}{|c|c|c|c|c|c|c|c|c|c|}
\hline $\begin{array}{l}\text { Species } \\
\text { (common } \\
\text { name) } \\
\end{array}$ & Genotype & $\begin{array}{c}\text { G-size }{ }^{\mathrm{a}} \\
\mathrm{Mb}\end{array}$ & Vector & R-site ${ }^{b}$ & $\begin{array}{l}\text { No. of } \\
\text { clones }\end{array}$ & $\begin{array}{l}\text { A.I-size } \\
\mathrm{kb}\end{array}$ & $\operatorname{Cov}^{\mathrm{d}}$ & $\mathrm{Use}^{\mathrm{e}}$ & Ref. $^{\mathrm{f}}$ \\
\hline \multirow{10}{*}{$\begin{array}{l}\text { Phaseolus } \\
\text { vulgaris } \mathrm{L} \text {. } \\
\text { (Common } \\
\text { bean) }\end{array}$} & Sprite & \multirow{10}{*}{636} & pECSBC4 & RcoRI & 33,792 & 100 & 5.3 & Ph.M. & {$[13]$} \\
\hline & Bat 93 & & pIndigoBac5 & HindIII & 110,592 & 125 & 21.7 & Evolution & {$[14]$} \\
\hline & G21245 & & pIndigoBac5 & HindIII & 55296 & 105 & 9.2 & Evolution & {$[14]$} \\
\hline & G02771 & & pIndigoBac5 & HindIII & 55296 & 139 & 12.1 & Evolution & {$[14]$} \\
\hline & G12949 & & pIndigoBac5 & HindIII & 30720 & 135 & 6.5 & cloning & {$[15]$} \\
\hline & G19833 & & pIndigoBac536 & HindIII & 55296 & 145 & 12.6 & Ph.M BES & {$[16]$} \\
\hline & HR45 & & pIndigoBac5 & HindIII & 33,024 & 107 & 5.5 & Ph.M.Cloning & {$[17]$} \\
\hline & HR67 & & BiBAC2 & BamHI & 22,560 & 300 & 10.6 & Cloning & {$[18]$} \\
\hline & OAC-Rex & & BiBAC2 & BamHI & 31,776 & 150 & 7.5 & Cloning & {$[18]$} \\
\hline & G02333 & & pBeloBac11 & HindIII & 24,960 & 125 & 4.9 & Cloning & {$[19]$} \\
\hline $\begin{array}{l}\text { P. lunatus L. } \\
\text { (Lima bean) }\end{array}$ & Henderson & 636 & pIndigoBac5 & HindIII & 55,296 & 110 & 9.6 & Evolution & {$[14]$} \\
\hline \multirow{2}{*}{$\begin{array}{l}\text { Vigna radiate } \\
\text { (Mungbean) }\end{array}$} & ACC41 & \multirow{2}{*}{587} & pBeloBacII & HindIII & 6,912 & 107 & 1.3 & Mar-dev. & {$[12]$} \\
\hline & ATT3640 & & pBeloBacII & BamHI & 11,904 & 113 & 2.3 & Mar-dev. & {$[12]$} \\
\hline \multirow{2}{*}{$\begin{array}{l}\text { V. unguiculata } \\
\text { (Cowpea) }\end{array}$} & IT97K-499-35 & \multirow{2}{*}{611} & $\mathrm{pCC} 1$ & HindIII & 36,864 & 150 & 9.1 & Cloning & {$[20]$} \\
\hline & IT97K-499-35 & & pCC1 & MboI & 36,864 & 130 & 7.8 & Cloning & {$[20]$} \\
\hline \multirow{5}{*}{$\begin{array}{l}\text { Cicer arietinum } \\
\text { (Chickpea) }\end{array}$} & FLIP84-92C & \multirow{5}{*}{758} & pCLDO4541 & HindIII & 23,780 & 100 & 3.1 & Cloning & {$[21]$} \\
\hline & Hadas & & pIndigoBac5 & HindIII & 14,976 & 121 & 2.4 & Mar-dev. & {$[22]$} \\
\hline & Hadas & & pCLD04541 & BamHI & 23,040 & 145 & 4.4 & Mar-dev. & {$[22]$} \\
\hline & Hadas & & $\mathrm{pECBAC1}$ & MboI & 22,272 & 130 & 3.8 & Ph.M & {$[23]$} \\
\hline & Hadas & & pCLD04541 & HindIII & 38,400 & 142 & 7.2 & Ph.M. & {$[23]$} \\
\hline \multirow{2}{*}{$\begin{array}{l}\text { Pisum sativum } \\
\text { (Pea) }\end{array}$} & PI269818 & 4397 & pCLD04541 & HindIII & 55,680 & 105 & 1.3 & & {$[24]$} \\
\hline & PI269818 & 4397 & pIndigoBac5 & HindIII & 65,280 & 105 & 2.2 & & {$[24]$} \\
\hline \multirow{2}{*}{$\begin{array}{l}\text { Cajanus cajan L. } \\
\text { (Pigeonpea) }\end{array}$} & Asha & \multirow{2}{*}{831} & pCC1BAC & HindIII & 34,560 & 120 & 5.0 & Mar-dev. & {$[25]$} \\
\hline & Asha & & pCC1BAC & BamHI & 34,560 & 115 & 4.8 & Mar-dev. & {$[25]$} \\
\hline $\begin{array}{l}\text { Lupinus } \\
\text { Angustifolius } \\
\text { (Lupin) }\end{array}$ & Sonet & 905 & pIndigoBac5 & HindIII & 55,296 & 100 & 6.1 & Karyotype & {$[26]$} \\
\hline \multicolumn{10}{|c|}{ 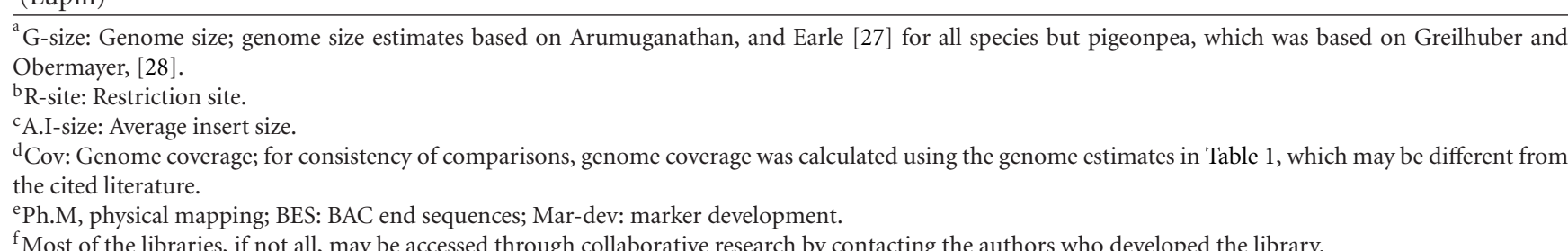 } \\
\hline
\end{tabular}

will further elucidate the organization of the $r$ gene complex and generate more tightly linked markers.

Lichtenzveig et al. [22] constructed both a BAC and a BIBAC (plant transformation-competent binary BAC) library of chickpea cv. Hadas (Table 1). Winter et al. noted that the abundant SSRs in chickpea have a high level of polymorphism and therefore would be useful for mapping and gene tagging [43]. Lichtenzveig screened the libraries with eight different synthetic oligos; sequenced the SSR regions with their flanking sequences of positive clones; designed primers complimentary to the flanking sequences. A total of 233 new SSR markers for chickpea were developed and characterized, which will be of significant value in further genomic studies.
A genome-wide BAC/BIBAC-based physical map of chickpea was developed by Zhang et al. using fingerprint analysis of four libraries, two of which were constructed for their study (Table 1) [23]. The map consists of 55,029 clones assembled into 1,945 contigs. Each contig contains 2 to $>199$ clones with an average of 28.3 clones per contig. The average contig size is $559 \mathrm{~kb}$, and the contigs collectively span $1,088 \mathrm{MB}$ that is $47 \%$ larger than the estimated size of the chickpea genome. This can be explained by overlap of contigs, underestimation of genome size, or overestimation of the average insert size of the source clones, the first explanation being most likely. The $10 \times$ coverage of the chickpea genome proved adequate to construct a highquality physical map sufficient for use in various aspects of 
chickpea genomics. The accuracy of the map was verified using independent contig building methods, different fingerprinting methods, and SSR marker hybridization [23].

Using their map, Zhang et al. identified three contigs that likely contain, or are closely linked to, the RDR QTL4.1, which accounted for $14.4 \%$ of the variability in Ascochyta blight resistance. They also identified a contig associated with DTF QTL8, which results in approximately four days earlier flowering, with early flowering being an advantage in escaping Ascochyta blight that tends to strike later in the season. In addition, since the physical map was constructed from both BAC and Agrobacterium-mediated plant transformation ready BIBACs, the inclusion of the BIBACs should facilitate cloning; promote functional analysis of the chickpea genome by genetic transformation at the whole genome level; improve the identification and utilization of QTL for other genes of agronomic interest $[23,48]$.

\section{Pigeonpea (Cajanus cajan L.)}

Pigeonpea (C. cajan L.) is an important food legume predominantly cultivated in tropical and subtropical regions. It is drought tolerant with a large range of maturities. Its seeds have $20-22 \%$ protein and are generally consumed as green peas, whole grain, or split peas. Pod husks are used as fodder and branches, and stems are used as domestic fuel [25].

Pigeonpea has a relatively low level of genetic diversity, which has made conventional breeding and development of genomic tools relatively ineffective [25]. In 2006, the Pigeonpea Genomics Initiative, with funding from the Indian Council of Agriculture and the US National Science Foundation, began an in-depth analysis of the pigeonpea genome. One result of this initiative was the development of a BAC library, made at UC Davis, from the reference genotype "Asha" that provides an $11 \times$ coverage of the $808 \mathrm{Mb}$ genome (Table 1).

This BAC library is an important resource for the development of molecular markers that can be used for MAS for desirable agronomic traits. Development of SSR markers from BAC-end sequences is very cost effective $[7,8]$ and offers genome-wide coverage as all repeat types are systematically sampled in the randomly selected BACs [9]. Varshney et al. end-sequenced 50,000 randomly selected clones from this BAC library generating a total of 87,590 BAC end sequences (BESs) [25]. These were screened with a microsatellite search module resulting in the identification of 18,149 SSRs representing 6,590 BAC clones. Amplified products were obtained from 2,565 of the designed primer pairs that will be used to identify polymorphism in a set of 24 pigeonpea genotypes [25].

Using NBS-LRR (nucleotide binding site-leucine-rich repeat disease resistance) homologues based on Medicago truncatula, researchers at UC Davis found 756 BAC clones that could form the basis for an SSR molecular resource linked to $90 \mathrm{BAC}$ contigs [25]. This information will be extremely useful in molecular breeding and disease-resistance dissection. Along with high-density molecular maps, transcription sequences, and so forth, the availability of a BAC library and all that it leads to could revolutionize pigeonpea crop improvement.

\section{Pea (Pisum sativum)}

Pea (P. sativum L.) is a relatively inexpensive and highly nutritious crop, and pea proteins are of great nutritional importance, being one of the major food legumes grown in different parts of the world [49]. Processed pea can be utilised in specific food formulations for preschool children to improve their protein intake. They are rich in lysine and complement cereals, producing an amino acid profile complying with the FAO reference pattern [50]. The pea genome is estimated to be $3947-4397 \mathrm{Mbp} / 1 \mathrm{C}$ or $10-30$ times the size of the genomes of Arabidopsis thaliana, Lotus japonicus, and Medicago truncatula [24]. Two BAC libraries of pea were constructed for the genotype PI 269818. One BAC library was constructed in the binary vector pCLD04541 for direct transformation of candidate pea gene BACs into plants [51]. The pCLD04541 library is composed of 55,680 clones with an average insert size of $105 \mathrm{~kb}$. The other library used the single-copy oriS-based vector (pIndigoBac5) and contains 65,280 clones with a mean insert size of $105 \mathrm{~kb}$. Partially HindIII-digested DNA fragments were cloned in both BAC vectors and the libraries encompassed about 3.2 $\times$ of the large haploid pea genome with about $1 \%$ of the clones from chloroplast and $0.1 \%$ of empty vectors [24]. Successful amplifications of low copy pea-specific resistance gene analogs (RGA) indicated that the libraries should be useful for many applications in genetic studies of pea.

\section{Common Bean (Phaseolus vulgaris $\mathbf{L}$.)}

Common bean (P. vulgaris) is grown and consumed principally in developing countries in Latin America, Africa, and Asia. It is largely a subsistence crop eaten by its producers and, hence, is underestimated in production and commerce statistics. Common bean is a major source of dietary protein, which complements carbohydrate-rich sources such as rice, maize, and cassava. It is also a rich source of dietary fibres, minerals, such as iron and zinc, and certain vitamins [18]. Among the eleven BAC libraries constructed in the genus Phaseolus today, ten of them were common bean $(P$. vulgaris) (Table 1). The first common bean BAC library was developed by Vanhouten and MacKenzie in 1999 with the Sprite snap bean-derived genotype for physical mapping of the nuclear fertility restorer Fr. locus [13]. In 2006, four BAC libraries, three for common bean genotypes BAT93, G21245, and G02771, and one for lima bean, cv. Henderson (P. lunatus), were developed to study the evolution of the arcelin-phytohemagglutinin-a-amylase inhibitor (APA) multigene family [14]. The four BAC libraries have a range of 9-20-fold genome coverage that should make them useful genetic resources for studying common bean and lima bean. The BAT 93 BAC library has been used successfully for cytogenetic studies of bean chromosomes [52, 53]. BAC libraries were also developed for common bean genotypes G19833 [16], G12949 [15], HR45 [17], G02333 [19], HR67 [18], and OAC-Rex [18]. 
The G19833 BAC library was used for BAC-end sequence analysis to develop BAC-derived SSR markers and for physical mapping of the common bean genome $[52,54]$. Liu et al. used the HR45 BAC library to physically map the major common bacterial bight (CBB) resistance QTL of common bean to the end of chromosome 6 [17]. Currently, the OAC-Rex BAC library is being used to sequence the whole genome of the $\mathrm{CBB}$ resistance cultivar, OAC-Rex (Pauls et al. personal communication), and whole genomic sequencing of G19833 is nearly completed (McClean et al. personal communication).

\section{Pros and Cons of BAC Library}

The yeast artificial chromosome (YAC) was first developed in 1983 [55], which can accommodate insert sizes upto 2 megabases $(\mathrm{Mb})$ that has overcome the size limitation of previous vectors. However, yeast spheroplast transformation is relatively inefficient, and large amounts of DNA are required for library construction [56]. YAC DNA, in addition, is linear and difficult to isolate intact due to its susceptibility to shear. Most importantly, YAC clones are often unstable and chimeric [57] in nature, and sequences with repetitious elements are prone to rearrangement or are unclonable [58].

$B A C s$ overcome many of the problems involved with YACs [2]. BACs can be transfected into E. coli by electroporation at efficiencies up to 100 times greater than yeast transformation. BAC DNA exists in supercoiled circular form that permits easy isolation and manipulation with minimal breaking. In addition, clones can be effortlessly isolated via miniprep alkaline lysis and directly reintroduced into bacterial cells. Importantly, bacterial recombination systems are well characterized, and recombination-deficient strains of E. coli are readily available. It is not surprising, then, that BAC DNA is very stable, a trait that is aided by the low copy numbers maintained in each cell. However, there are $\mathrm{BAC}$ vectors that can attain very high copy numbers while maintaining DNA stability [59].

One drawback of BAC vectors compared to YAC vectors is that the maximum insert size that BACs can accommodate merely exceeds $300 \mathrm{~kb}$ although clones in the mid- $300 \mathrm{~kb}$ range are obtainable. Additionally, the number of successfully generated clones decreases when attempting to achieve higher insert sizes, and there has been suggestion that there are species-specific library insert-size limitations based on base-pair content and sequence dissimilarities [60]. In addition, BAC insert rearrangement can occur in the early stage of library construction and duplication [61]. Furthermore, BAC clones containing tandemly repeated DNA sequences are not stable in $E$. coli during routine maintenance and propagation. BAC vectors also suffer from problems of cloning bias, that is, rearrangement or loss of DNA segments containing AT- or GC-rich regions, strong promoters, repeats, hairpins, toxic genes, or other sequences. They also suffer from empty vector background and relatively few recombinants per reaction [62]. Since BAC libraries are usually developed by cloning size-fractionated DNA fragments partially digested with restriction enzymes, gaps in the physical maps can be created either by nonrandom distribution of the restriction sites for any enzyme in genomic DNA [63] or by nonclonable or unstable DNA segments in the E. Coli host [64]. As an alternative, the fosmid cloning system is rapidly emerging as a method of choice to rapidly create high-titer "mini-BAC libraries" with an average insert size of $40 \mathrm{~kb}$ [65]. Because the genomic DNA used in fosmid library construction is usually mechanically shared, fosmid libraries are quite useful for closing gaps in physical mapping [66]. Today, the improved fosmid vector from Lucigen can accommodate DNA fragment as large as $90 \mathrm{~kb}$ [http://lucigen.com/store/Custom-Fosmid-Libraries.html].

Although the problems above mentioned were not reported for the BAC libraries developed in pulse crops, instability associated with insert size over $100 \mathrm{~kb}$ was observed in potato [67]. The mechanism of the instability of BAC clones is unknown. It is likely that the current BAC vectors and a host strain like DH10B are not able to stably maintain DNA sequences with certain unique features, including tandemly repeated sequences. Therefore, it may be possible to partially or completely overcome the BAC instability problem by selecting appropriate E. coli strains [67].

\section{Summary and Future Prospects}

In summary, twenty-five BAC libraries of pulse crops have been reported in the literature. The BAC libraries are important genomic resources that have been used for (1) physical mapping of pulse genomes, (2) molecular marker development of microsatellite markers, (3) map-based cloning of genes or QTL for important agronomic traits, (4) evolutionary study of multigene families, (5) karyotyping genomes through BAC-FISH, and (6) whole genomic sequencing.

Looking into the future, the BACs of pulse crops should have potential applications in pulse comparative genomics and functional genomics in addition to those above-mentioned. It is well known that macro- and microsynteny are widespread within legumes. Based on 1000 anchored BAC ends, more than half of all soybean BAC contig groups exhibit microsynteny with Medicago truncatula [68]. By comparing BAC end sequences, microsynteny was found among M. truncatula, G. max, and Lotus japonicus [69]. Significant macro- and microsynteny were observed among $G$. max, P. vulgaris and Vigna radiata [70]. Large-scale macrosyntenic blocks were also observed among $P$. vulgaris, M. truncatula, and L. japonicus [71]. Because extensive genomic information is available for soybean (http://soybase .org/), medicago (http://gbrowse.jcvi.org/cgi-bin/gbrowse/ medicago/\#search), and Lotus (http://www.plantgdb.org/ LjGDB/), the genetic synteny between pulse and the model legume species will help pulse researchers to speed up the understanding of pulse genomes by comparative genomics (http://www.comparative-legumes.org/).

Most of the BAC applications in pulse crops to date are of structural genomics nature; however, the application of BACs in functional genomics analysis of pulses also has great potential. Since large insert clones in BAC vectors are more likely to contain the necessary promoter, enhancer, and silencer combination, mimicking the natural expression of 
the gene of interest, the advantages of the BAC transgenic approach are significant compared to the conventional transgenic approach [72]. Since the presence of appropriate regulatory elements could cause a gene in BACs to be expressed with spatial and temporal accuracy at similar levels to the endogenous loci, the integration site effects experienced by conventional gene transformation methods might be eliminated or reduced [73]. In addition, the ability of modification techniques to insert or delete sequences or alter sequences as discrete as a single-point mutation could make the BAC transgenic system a powerful tool for addressing both mechanistic and functional questions.

\section{Acknowledgments}

The author acknowledges the financial supports from Ontario White Bean and Colored Bean Producers and Agriculture and Agri-Food Canada. Critical review of the paper by Dr. V. Poysa is gratefully acknowledged as well.

\section{References}

[1] F. Hosoda, S. Nishimura, H. Uchida, and M. Ohki, "An F factor based cloning system for large DNA fragments," Nucleic Acids Research, vol. 18, no. 13, pp. 3863-3869, 1990.

[2] H. Shizuya, B. Birren, U. J. Kim et al., "Cloning and stable maintenance of 300-kilobase-pair fragments of human DNA in Escherichia coli using an F-factor-based vector," Proceedings of the National Academy of Sciences of the United States of America, vol. 89, no. 18, pp. 8794-8797, 1992.

[3] S. D. Tanksley, M. W. Ganal, and G. B. Martin, "Chromosome landing: a paradigm for map-based gene cloning in plants with large genomes," Trends in Genetics, vol. 11, no. 2, pp. 63-68, 1995.

[4] H. B. Zhang, S. Choi, S. S. Woo, Z. Li, and R. A. Wing, "Construction and characterization of two rice Bacterial Artificial Chromosome libraries from the parents of a permanent recombinant inbred mapping population," Molecular Breeding, vol. 2, no. 1, pp. 11-24, 1996.

[5] G.-L. Wang, T. E. Holsten, W.-Y. Song, H.-P. Wang, and P. C. Ronald, "Construction of a rice bacterial artificial chromosome library and identification of clones linked to the Xa-21 disease resistance locus," Plant Journal, vol. 7, no. 3, pp. 525-533, 1995.

[6] S. S. Woo, J. Jiang, B. S. Gill, A. H. Paterson, and R. A. Wing, "Construction and characterization of a bacterial artificial chromosome library of Sorghum bicolor," Nucleic Acids Research, vol. 22, no. 23, pp. 4922-4931, 1994.

[7] J. L. Shultz, S. Kazi, R. Bashir, J. A. Afzal, and D. A. Lightfoot, "The development of BAC-end sequence-based microsatellite markers and placement in the physical and genetic maps of soybean," Theoretical and Applied Genetics, vol. 114, no. 6, pp. 1081-1090, 2007.

[8] S. Temnykh, G. DeClerck, A. Lukashova, L. Lipovich, S. Cartinhour, and S. McCouch, "Computational and experimental analysis of microsatellites in rice (Oryza sativa L.): frequency, length variation, transposon associations, and genetic marker potential," Genome Research, vol. 11, no. 8, pp. 1441-1452, 2001.

[9] S. Cho, W. Chen, and F. J. Muehlbauer, "Pathotype-specific genetic factors in chickpea (Cicer arietinum $\mathrm{L}$.) for quantitative resistance to ascochyta blight," Theoretical and Applied Genetics, vol. 109, no. 4, pp. 733-739, 2004.

[10] M. O'Connor, M. Peifer, and W. Bender, "Construction of large DNA segments in Escherichia coli," Science, vol. 244, no. 4910, pp. 1307-1312, 1989.

[11] R. J. Lawn, "The asiatic Vigna species. Vigna spp (V. radiata, $V$. mungo, V. angularis, V. unbellata and V. acontifolia) (Leguminosae-Papilionoideae)," in Evolution of Crop Plants, J. Smartt and N. Simmonds, Eds., pp. 321-326, John Wiley \& Sons, New York, NY, USA, 2nd edition, 1995.

[12] M. Miyagi, M. Humphry, Z. Y. Ma, C. J. Lambrides, M. Bateson, and C. J. Liu, "Construction of bacterial artificial chromosome libraries and their application in developing PCR-based markers closely linked to a major locus conditioning bruchid resistance in mungbean (Vigna radiata L. Wilczek)," Theoretical and Applied Genetics, vol. 110, no. 1, pp. 151-156, 2004.

[13] W. Vanhouten and S. MacKenzie, "Construction and characterization of a common bean bacterial artificial chromosome library," Plant Molecular Biology, vol. 40, no. 6, pp. 977-983, 1999.

[14] J. Kami, V. Poncet, V. Geffroy, and P. Gepts, "Development of four phylogenetically-arrayed BAC libraries and sequence of the APA locus in Phaseolus vulgaris," Theoretical and Applied Genetics, vol. 112, no. 6, pp. 987-998, 2006.

[15] I. Galasso, A. R. Piergiovanni, L. Lioi, B. Campion, R. Bollini, and F. Sparvoli, "Genome organization of Bowman-Birk inhibitor in common bean (Phaseolus vulgaris L.)," Molecular Breeding, vol. 23, no. 4, pp. 617-624, 2009.

[16] J. A. Schlueter et al., "BAC-end sequence analysis and a draft physical map of the common bean (Phaseolus vulgaris L.) Genome," Tropical Plant Biology, vol. 1, pp. 40-48, 2008.

[17] S. Y. Liu, K. Yu, M. Huffner et al., "Construction of a BAC library and a physical map of a major QTL for CBB resistance of common bean (Phaseolus vulgaris L.)," Genetica, vol. 138, no. 7, pp. 709-716, 2010.

[18] P. Gepts et al., "Genomics of phaseolus beans, a major source of dietary protein and micronutrients in the tropics," in Genomics of Tropical Crop Plants, P. H. Moore and R. Ming, Eds., pp. 113-143, Springer, New York, NY, USA, 2008.

[19] M. Melotto, C. Fransisco, and L. E. A. Camargo, "Towards cloning the Co-42 locus using a bean BAC library," Bean Improvement Cooperative Annual Report, vol. 46, pp. 51-52, 2003.

[20] Y. Ma et al., "Genomic resources of cowpea (Vigna unguiculata)," in Proceedings of the 17th Plant and Animal Genome Conference, p. 393, 2009.

[21] P. N. Rajesh, C. Coyne, K. Meksem, K. D. Sharma, V. Gupta, and F. J. Muehlbauer, "Construction of a HindIII Bacterial Artificial Chromosome library and its use in identification of clones associated with disease resistance in chickpea," Theoretical and Applied Genetics, vol. 108, no. 4, pp. 663-669, 2004.

[22] J. Lichtenzveig, C. Scheuring, J. Dodge, S. Abbo, and H. B. Zhang, "Construction of BAC and BIBAC libraries and their applications for generation of SSR markers for genome analysis of chickpea, Cicer arietinum L," Theoretical and Applied Genetics, vol. 110, no. 3, pp. 492-510, 2005.

[23] X. Zhang, C. F. Scheuring, M. Zhang et al., "A BAC/BIBACbased physical map of chickpea, Cicer arietinum L," BMC Genomics, vol. 11, no. 1, article 501, 2010.

[24] C. J. Coyne, M. T. McClendon, J. G. Walling et al., "Construction and characterization of two bacterial artificial chromosome libraries of pea (Pisum sativum L.) for the isolation 
of economically important genes," Genome, vol. 50, no. 9, pp. 871-875, 2007.

[25] R. K. Varshney, R. V. Penmetsa, S. Dutta et al., "Pigeonpea genomics initiative (PGI): an international effort to improve crop productivity of pigeonpea (Cajanus cajan L.)," Molecular Breeding, vol. 26, no. 3, pp. 393-408, 2010.

[26] A. Kasprzak, J. Šafář, J. Janda, J. Doležel, B. Wolko, and B. Naganowska, "The bacterial artificial chromosome (BAC) library of the narrow-leafed lupin (Lupinus angustifolius L.)," Cellular and Molecular Biology Letters, vol. 11, no. 3, pp. 396407, 2006.

[27] K. Arumuganathan and E. D. Earle, "Nuclear DNA content of some important plant species," Plant Molecular Biology Reporter, vol. 9, no. 3, pp. 208-218, 1991.

[28] J. Greilhuber and R. Obermayer, "Genome size variation in Cajanus cajan (Fabaceae): a reconsideration," Plant Systematics and Evolution, vol. 212, no. 1-2, pp. 135-141, 1998.

[29] D. S. Petterson and D. J. Harris, "Cadmium and lead content of lupin seed grown in Western Australia," Australian Journal of Experimental Agriculture, vol. 35, no. 3, pp. 403-407, 1995.

[30] A. Kaczmarek, B. Naganowska, and B. Wolko, "Karyotyping of the narrow-leafed lupin (Lupinus angustifolius L.) by using FISH, PRINS and computer measurements of chromosomes," Journal of Applied Genetics, vol. 50, no. 2, pp. 77-82, 2009.

[31] M. N. Nelson, P. M. Moolhuijzen, J. G. Boersma et al., "Aligning a new reference genetic map of lupinus angustifolius with the genome sequence of the model legume, lotus japonicus,” DNA Research, vol. 17, no. 2, pp. 73-83, 2010.

[32] M. P. Timko, J. D. Ehlers, and P. A. Roberts, "Cowpea," in Gene Mapping and Molecular Breeding in Plants, K. Chittaranjan, Ed., vol. 3, Springer, New York, NY, USA, 2007.

[33] J. M. Ribaut, "International programs and the use of medern biotechnologies for crop improvement," in Genomics of Tropical Crop Plants, P. Moore and R. Ming, Eds., pp. 21-63, Springer, New York, NY, USA, 2008.

[34] R. K. Varshney, J. C. Glaszmann, H. Leung, and J. M. Ribaut, "More genomic resources for less-studied crops," Trends in Biotechnology, vol. 28, no. 9, pp. 452-460, 2010.

[35] M. C. Luo, C. Thomas, F. M. You et al., "High-throughput fingerprinting of bacterial artificial chromosomes using the SNaPshot labeling kit and sizing of restriction fragments by capillary electrophoresis," Genomics, vol. 82, no. 3, pp. 378389, 2003.

[36] L. Maesen and J. G. van der, "Origin, history and taxomony of chickpea," in The Chickpea, M. C. Saxena and K. B. Singh, Eds., pp. 11-34, CAB International, Wallingford, UK, 1987.

[37] H. Flandez-Galvez, R. Ford, E. C. K. Pang, and P. W. J. Taylor, "An intraspecific linkage map of the chickpea (Cicer arietinum L.) genome based on sequence tagged microsatellite site and resistance gene analog markers," Theoretical and Applied Genetics, vol. 106, no. 8, pp. 1447-1456, 2003.

[38] H. Flandez-Galvez, P. K. Ades, R. Ford, E. C. K. Pang, and P. W. J. Taylor, "QTL analysis for ascochyta blight resistance in an intraspecific population of chickpea (Cicer arietinum L.)," Theoretical and Applied Genetics, vol. 107, no. 7, pp. 12571265, 2003.

[39] M. Tekeoglu, D. K. Santra, W. J. Kaiser, and F. J. Muehlbauer, "Ascochyta blight resistance inheritance in three chickpea recombinant inbred line populations," Crop Science, vol. 40, no. 5, pp. 1251-1256, 2000.

[40] L. D. Robertson, B. Ocampo, and K. B. Singh, "Morphological variation in wild annual Cicer species in comparison to the cultigen," Euphytica, vol. 95, no. 3, pp. 309-319, 1997.
[41] B. C. Y. Collard, E. C. K. Pang, P. K. Ades, and P. W. J. Taylor, "Preliminary investigation of QTLs associated with seedling resistance to ascochyta blight from Cicer echinospermum, a wild relative of chickpea," Theoretical and Applied Genetics, vol. 107, no. 4, pp. 719-729, 2003.

[42] C. J. Simon and F. J. Muehlbauer, "Construction of a chickpea linkage map and its comparison with maps of pea and lentil," Journal of Heredity, vol. 88, no. 2, pp. 115-119, 1997.

[43] P. Winter, A. M. Benko-Iseppon, B. Hüttel et al., "A linkage map of the chickpea (Cicer arietinum L.) genome based on recombinant inbred lines from a C. arietinum $\mathrm{x}$ C. reticulatum cross: localization of resistance genes for Fusarium wilt races 4 and 5," Theoretical and Applied Genetics, vol. 101, no. 7, pp. 1155-1163, 2000.

[44] T. Pfaff and G. Kahl, "Mapping of gene-specific markers on the genetic map of chickpea (Cicer arietinum L.)," Molecular Genetics and Genomics, vol. 269, no. 2, pp. 243-251, 2003.

[45] M. Tekeoglu, P. N. Rajesh, and F. J. Muehlbauer, "Integration of sequence tagged microsatellite sites to the chickpea genetic map," Theoretical and Applied Genetics, vol. 105, no. 6-7, pp. 847-854, 2002.

[46] D. K. Santra, M. Tekeoglu, M. Ratnaparkhe, W. J. Kaiser, and F. J. Muehlbauer, "Identification and mapping of QTLs conferring resistance to Ascochyta blight in chickpea," Crop Science, vol. 40, no. 6, pp. 1606-1612, 2000.

[47] S. M. Udupa and M. Baum, "Genetic dissection of pathotypespecific resistance to ascochyta blight disease in chickpea (Cicer arietinum L.) using microsatellite markers," Theoretical and Applied Genetics, vol. 106, no. 7, pp. 1196-1202, 2003.

[48] A. E. Men, K. Meksem, M. A. Kassem et al., "A bacterial artificial chromosome library of lotus japonicus constructed in an Agrobacterium tumefaciens-transformable vector," Molecular Plant-Microbe Interactions, vol. 14, no. 3, pp. 422-425, 2001.

[49] A. Iqbal, I. A. Khalil, N. Ateeq, and M. Sayyar Khan, "Nutritional quality of important food legumes," Food Chemistry, vol. 97, no. 2, pp. 331-335, 2006.

[50] FAO, "Protein and amino acid requirements in human nutrition," Report of Joint WHO/FAO/UNU Expert Consultation 935, 2007.

[51] Q. Tao and H. B. Zhang, "Cloning and stable maintenance of DNA fragments over $300 \mathrm{~kb}$ in Escherichia coli with conventional plasmid-based vectors," Nucleic Acids Research, vol. 26, no. 21, pp. 4901-4909, 1998.

[52] A. Fonsêca, J. Ferreira, T. R. B. Dos Santos et al., "Cytogenetic map of common bean (Phaseolus vulgaris L.)," Chromosome Research, vol. 18, no. 4, pp. 487-502, 2010.

[53] A. Pedrosa-Harand, J. Kami, P. Gepts, V. Geffroy, and D. Schweizer, "Cytogenetic mapping of common bean chromosomes reveals a less compartmentalized small-genome plant species," Chromosome Research, vol. 17, no. 3, pp. 405-417, 2009.

[54] J. M. Córdoba, C. Chavarro, J. A. Schlueter, S. A. Jackson, and M. W. Blair, "Integration of physical and genetic maps of common bean through BAC-derived microsatellite markers," BMC Genomics, vol. 11, no. 1, article 436, 2010.

[55] A. W. Murray and J. W. Szotsak, "Construction of artificial chromosomes in yeast," Nature, vol. 305, no. 5931, pp. 189193, 1983.

[56] A. P. Monaco and Z. Larin, "YACs, BACs, PACs and MACs: artificial chromosomes as research tools," Trends in Biotechnology, vol. 12, no. 7, pp. 280-286, 1994.

[57] E. D. Green, H. C. Riethman, J. E. Dutchik, and M. V. Olson, "Detection and characterization of chimeric yeast 
artificial-chromosome clones," Genomics, vol. 11, no. 3, pp. 658-669, 1991.

[58] P. A. Ioannou and P. J. de Jong, "Construction of bacterial artificial chromosome libraries using the modified P1 (PAC) system," in Current Protocols in Human Genetics, N. C. Dracopoli, J. L. Haines, B. R. Korf et al., Eds., pp. 1-24, John Wiley \& Sons, New York, NY, USA, 1996.

[59] E. Frengen, D. Weichenhan, B. Zhao, K. Osoegawa, M. Van Geel, and P. J. De Jong, "A modular, positive selection bacterial artificial chromosome vector with multiple cloning sites," Genomics, vol. 58, no. 3, pp. 250-253, 1999.

[60] M. R. Rondon, S. J. Raffel, R. M. Goodman, and J. Handelsman, "Toward functional genomics in bacteria: analysis of gene expression in Escherichia coli from a bacterial artificial chromosome library of Bacillus cereus," Proceedings of the National Academy of Sciences of the United States of America, vol. 96, no. 11, pp. 6451-6455, 1999.

[61] J. Song, F. Dong, J. W. Lilly, R. M. Stupar, and J. Jiang, "Instability of bacterial artificial chromosome (BAC) clones containing tandemly repeated DNA sequences," Genome, vol. 44, no. 3, pp. 463-469, 2001.

[62] J. Wild, Z. Hradecna, and W. Szygbalski, "Conditionally amplifiable BACs: switching from single-copy to high-copy vectors and genomic clones," Genome Research, vol. 12, no. 9, pp. 1434-1444, 2002.

[63] M. Chen, G. Presting, W. B. Barbazuk et al., "An integrated physical and genetic map of the rice genome," Plant Cell, vol. 14, no. 3, pp. 537-545, 2002.

[64] S. V. Razin, E. S. Ioudinkova, E. N. Trifonov, and K. Scherrer, "Non-clonability correlates with genomic instability: a case study of a unique DNA region," Journal of Molecular Biology, vol. 307, no. 2, pp. 481-486, 2001.

[65] U. J. Kim, H. Shizuya, P. J. De Jong, B. Birren, and M. I. Simon, "Stable propagation of cosmid sized human DNA inserts in an F factor based vector," Nucleic Acids Research, vol. 20, no. 5, pp. 1083-1085, 1992.

[66] J. S. S. Ammiraju, Y. Yu, M. Luo et al., "Random sheared fosmid library as a new genomic tool to accelerate complete finishing of rice (Oryza sativa spp. Nipponbare) genome sequence: sequencing of gap-specific fosmid clones uncovers new euchromatic portions of the genome," Theoretical and Applied Genetics, vol. 111, no. 8, pp. 1596-1607, 2005.

[67] J. Song, J. M. Bradeen, S. K. Naess, J. P. Helgeson, and J. Jiang, "BIBAC and TAC clones containing potato genomic DNA fragments larger than $100 \mathrm{~kb}$ are not stable in Agrobacterium," Theoretical and Applied Genetics, vol. 107, no. 5, pp. 958-964, 2003.

[68] H. H. Yan, J. Mudge, D. J. Kim, B. C. Shoemaker, D. R. Cook, and N. D. Young, "Comparative physical mapping reveals features of microsynteny between Glycine max, Medicago truncatula, and Arabidopsis thaliana," Genome, vol. 47, no. 1, pp. 141-155, 2004.

[69] S. B. Cannon, W. R. McCombie, S. Sato et al., "Evolution and microsynteny of the apyrase gene family in three legume genomes," Molecular Genetics and Genomics, vol. 270, no. 4, pp. 347-361, 2003.

[70] J. M. Lee, D. Grant, C. E. Vallejos, and R. C. Shoemaker, "Genome organization in dicots. II. Arabidopsis as a 'bridging species' to resolve genome evolution events among legumes," Theoretical and Applied Genetics, vol. 103, no. 5, pp. 765-773, 2001.

[71] M. McConnell, S. Mamidi, R. Lee et al., "Syntenic relationships among legumes revealed using a gene-based genetic linkage map of common bean (Phaseolus vulgaris L.)," Theoretical and Applied Genetics, vol. 121, no. 6, pp. 1103-1116, 2010.

[72] X. W. Yang and S. Gong, "An overview on the generation of BAC transgenic mice for neuroscience research," Current Protocols in Neuroscience, vol. 5, unit 5.20, 2005.

[73] S. Gong, C. Zheng, M. L. Doughty et al., "A gene expression atlas of the central nervous system based on bacterial artificial chromosomes," Nature, vol. 425, no. 6961, pp. 917-925, 2003. 

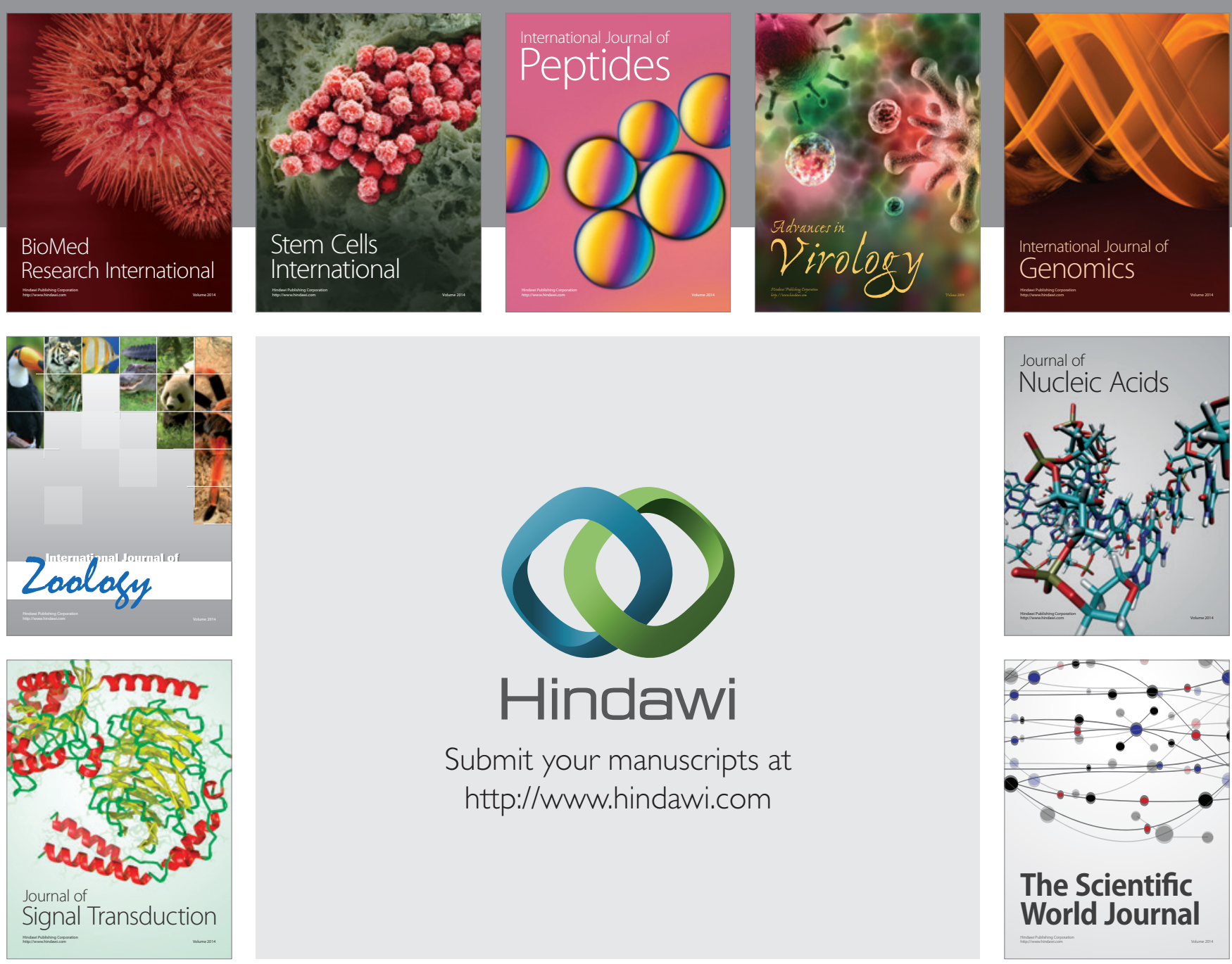

Submit your manuscripts at

http://www.hindawi.com
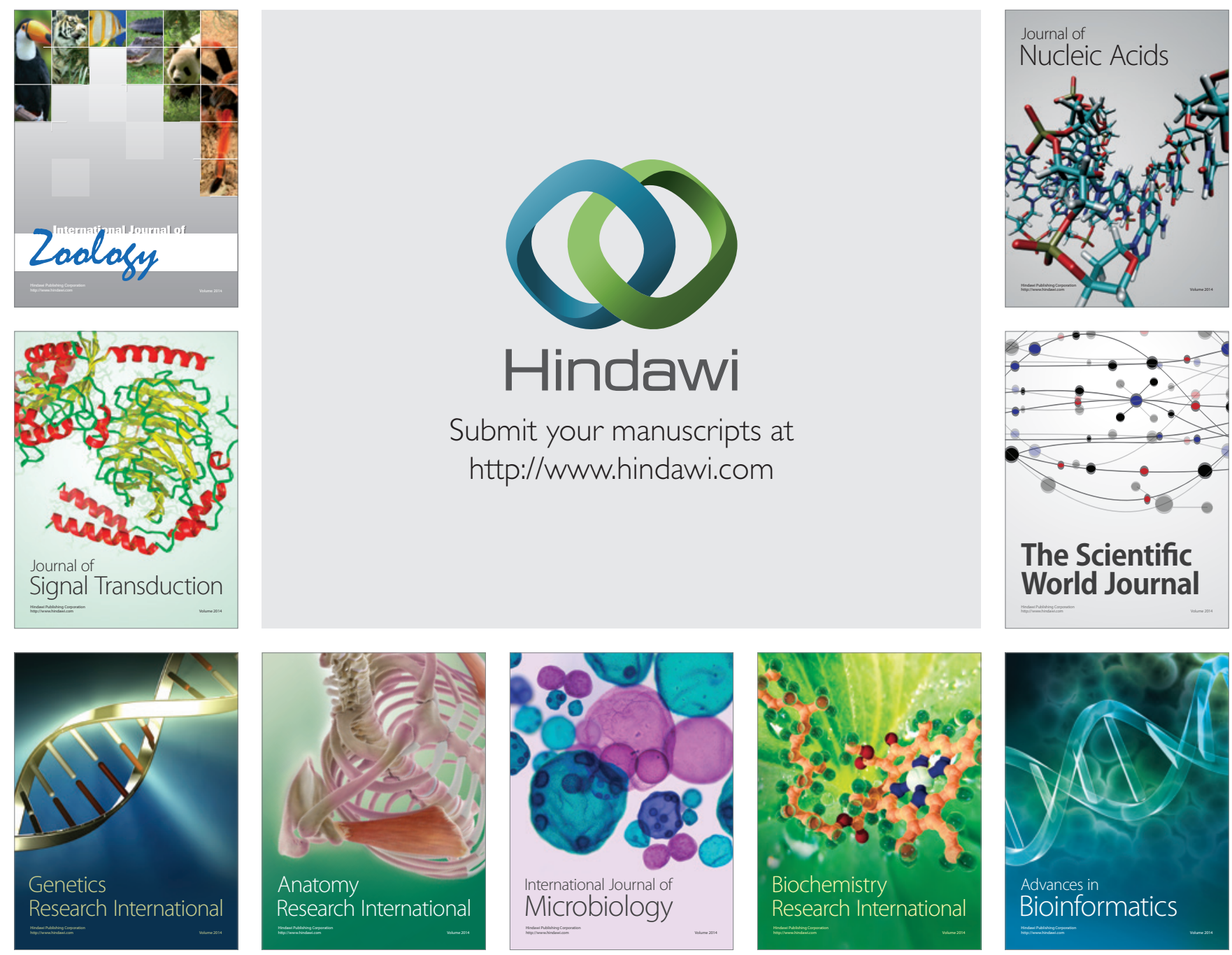

The Scientific World Journal
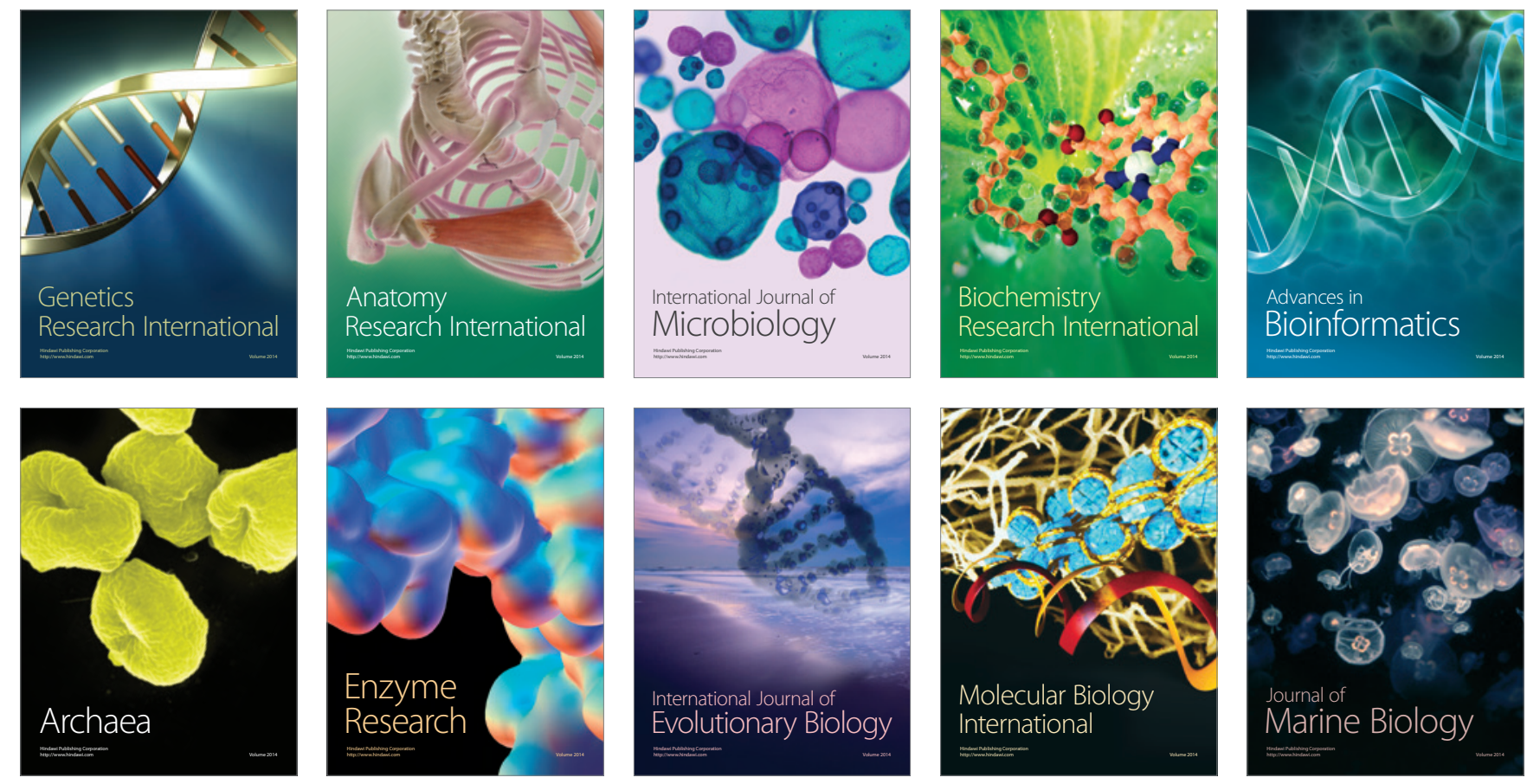